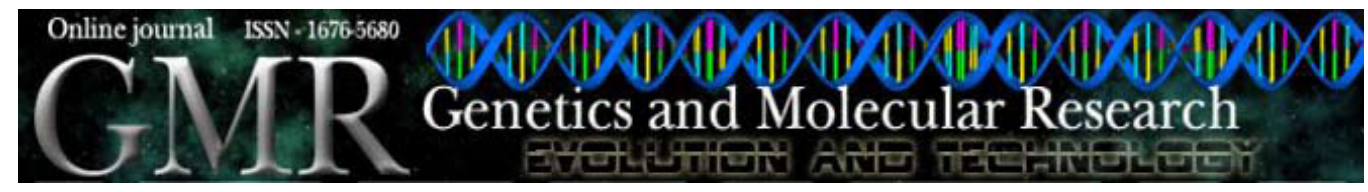

\title{
Different responses to doxorubicin-induced chromosome aberrations in Brazilian deer species
}

\author{
D.S.F. Vargas-Munar, J.A. Sarria-Perea and J.M.B. Duarte \\ Núcleo de Pesquisa e Conservação de Cervídeos, \\ Departamento de Genética e Melhoramento Animal, \\ Universidade Estadual Paulista, Jaboticabal, SP, Brasil \\ Corresponding author: J.A. Sarria-Perea \\ E-mail: jasarrip@yahoo.com
}

Genet. Mol. Res. 9 (3): 1545-1549 (2010)

Received March 17, 2010

Accepted June 26, 2010

Published August 10, 2010

DOI 10.4238/vol9-3gmr822

\begin{abstract}
The tendency toward chromosome fragility is one of the theories that may explain chromosome variation in brocket deer species (genus Mazama). We tested doxorubicin as an inducer of chromosome aberrations in lymphocytes of three brocket deer species, Mazama gouazoubira, M. americana and M. nana, compared to the marsh deer, Blastocerus dichotomus. Doxorubicin, at a concentration of $0.25 \mu \mathrm{g} / \mathrm{mL}$, induced chromosome aberrations and fragile sites in all four species; the highest frequencies were seen in M. gouazoubira; they were lowest in B. dichotomus and intermediate in M. americana and M. nana. These results were expected based on previous karyotypic studies, but they failed to explain the higher sensitivity seen in M. gouazoubira. This may be because not all the aberrations and fragile sites are related to chromosome evolution in brocket deer; other factors, such as environmental influences, may be involved in chromosome fragility.
\end{abstract}

Key words: Blastocerus; Cervidae; Chromosome evolution; Chromosome fragility; Mazama 


\section{INTRODUCTION}

Cytogenetics and molecular phylogenetics have contributed greatly to the knowledge of the evolutionary complexity of deer family Cervidae (Neitzel, 1987; Fontana and Rubini, 1990), particularly those of the genus Mazama (Mammalia; Cervidae), a group of small to medium-sized forest deer with spike-like antlers from Central and South America, characterized by their phenotypic homogeny in the presence of a polyphyletic origin (Gilbert et al., 2006; Duarte et al., 2008). Some cytogenetic studies have demonstrated very complex processes of chromosome evolution, being more intense in the reddish brocket group (Mazama americana, M. nana and M. bororo) than in grayish brockets (M. gouazoubira and M. nemorivaga). Duarte and Merino (1997) found a frequency of $20 \%$ single Robertsonian translocations in 77 M. gouazoubira analyzed, while other studies demonstrated that M. americana and M. nana had an unusual karyotypic diversity, varying from $2 n=42$ to 53 and from $2 n=34$ to 40 , respectively, in both cases as a consequence of extensive and complex chromosome rearrangements (Duarte and Jorge, 1996; Abril and Duarte, 2008). In contrast, the marsh deer Blastocerus dichotomus showed karyotypic stability, with no chromosome rearrangements in 35 animals analyzed (Duarte and Giannoni, 1995).

The tendency toward chromosome fragility is one of the theories that may explain the chromosome variation in brocket species (Duarte and Jorge, 1996). Chromosome fragility has been associated with karyotypic evolution in some mammalian species such as the rock wallabies of the genus Petrogale (Eldridge and Johnston, 1993) and primates of the family Cebidae (Mudry et al., 1995). It also has been associated with cancer (Miró et al., 1987; Yunis et al., 1987). In order to detect fragile sites, several agents have been tested, such as ionizing radiation, chemical reagents and microorganisms, including viruses (Eldridge and Johnston, 1993). However, very few studies have been carried out for this purpose in deer species. Gripenberg et al. (1991) tested 5-bromo-2-deoxyuridine (BrdU) as an inducer of fragile sites in four deer species, and found that three of them were refractory to the agent and only one, the reindeer Rangifer tarandus, consistently expressed a fragile site on the X-chromosome.

Given 1) our interest in testing the expression of fragile sites in some Brazilian deer species to determine their possible relationship with chromosome evolution and 2) the necessity to test other inducers of fragile sites since BrdU was ineffective for this purpose, we tested doxorubicin (DXR), also known as Adriamycin, an anthracycline antibiotic. DXR is a potent chemotherapeutic agent used in the treatment of breast and esophageal carcinoma among other types of cancer (Gülkaç et al., 2004). It is known that DXR induces mutations and chromosomal aberrations in normal and tumor cells (Au and Hsu, 1980; Antunes and Takahashi, 1998), and it has been proven that DXR produces chromosome aberrations in cell cultures (Vig, 1971). The goals of this study were 1) to test the ability of DXR to induce chromosome aberrations in deer and 2) to determine its potential use in future studies of chromosome fragility and evolution in brockets and other deer species.

\section{MATERIAL AND METHODS}

We collected samples of peripheral blood from two individuals each of M. americana, M. nana, M. gouazoubira, and B. dichotomus. Lymphocytes were cultured in $8 \mathrm{~mL}$ Ham's F10 medium enriched with $20 \%$ horse serum, supplemented with $0.4 \mathrm{~mL}$ Phaseolus vulgaris extract and incubated at $38^{\circ} \mathrm{C}$ for $72 \mathrm{~h}$. For the induction of chromosome aberrations, the cultures were 
supplemented with seven different concentrations of DXR (Adriblastin ${ }^{\circledR}$ Pharmacia) varying from 0.10 to $0.40 \mu \mathrm{g} / \mathrm{mL}$ in increments of $0.05 \mu \mathrm{g} / \mathrm{mL}$. We opted to use the concentration of $0.25 \mu \mathrm{g} / \mathrm{mL}$ because it was able to induce aberrations in all four Brazilian deer species tested; lower concentrations produced no induction and higher concentrations were highly toxic to cells, impairing culture growth. DXR was added $48 \mathrm{~h}$ before the beginning of the incubation. Additional cultures without DXR were grown for each individual, as control cultures.

Harvesting was carried out according to standard protocols (Moorhead et al., 1960), and slides of both DXR-treated and DXR-free cells were stained with 10\% Giemsa. A total of 100 metaphases per culture were analyzed, and the chromosome aberrations seen were counted and classified according to Savage (1976). In order to evaluate differences in frequency of chromosomal aberrations and total chromosomal aberrations in DXR-treated metaphases, one-way ANOVA was conducted, and the mean values for these features were analyzed using the Tukey test at $\mathrm{P}<0.05$.

\section{RESULTS}

Compared to human cells, deer are apparently less sensitive to DXR, since the highest concentration tested in humans was $0.15 \mu \mathrm{g} / \mathrm{mL}$, inducing two to three times more chromosome aberrations (Vig, 1971), probably indicating more genomic stability in deer than humans. When comparing the different deer species, the highest aberration frequencies were seen in $M$. gouazoubira and the lowest in B. dichotomus. Aberration frequencies in M. americana and $M$. nana were lower than in M. gouazoubira but higher than in B. dichotomus. Differences in the induction of chromosome aberrations were not statistically significant between M. americana and M. nana. The aberrations most frequently seen were chromatid breaks and gaps, while other aberrations such as isochromatid breaks, triradials and chromosomal exchanges were rarely seen. All types of aberrations were observed only in M. gouazoubira. The results are shown in Table 1.

\begin{tabular}{|c|c|c|c|c|c|c|c|c|c|}
\hline \multirow[t]{3}{*}{ Species } & \multirow[t]{3}{*}{$2 n$} & \multirow[t]{3}{*}{ Treatment } & \multicolumn{5}{|c|}{ Frequency of aberrations* } & \multirow[t]{3}{*}{ Total aberrations** } & \multirow[t]{3}{*}{$\mathrm{MA}^{* *}$} \\
\hline & & & \multicolumn{2}{|c|}{ Breaks } & \multirow[t]{2}{*}{ Gaps } & \multirow[t]{2}{*}{ Triradial } & \multirow[t]{2}{*}{ Exchange } & & \\
\hline & & & $\mathrm{C}$ & IC & & & & & \\
\hline \multirow[t]{2}{*}{ M. gouazoubira } & \multirow[t]{2}{*}{70} & Control & 3 & 0 & 3 & 0 & 0 & 6 & 6 \\
\hline & & DXR & 58.5 & 1.5 & 46 & 2 & 3 & $108.5^{\mathrm{a}}$ & $62.5^{\mathrm{a}}$ \\
\hline \multirow[t]{2}{*}{ M. americana } & \multirow[t]{2}{*}{52} & Control & 2 & 0 & 3 & 0 & 0 & 5 & 5 \\
\hline & & DXR & 26 & 0 & 43.5 & 1 & 0.5 & $72^{\mathrm{b}}$ & $49.5^{\mathrm{b}}$ \\
\hline \multirow[t]{2}{*}{ M. nana } & \multirow[t]{2}{*}{36} & Control & 2 & 0 & 1 & 0 & 0 & 3 & 3 \\
\hline & & DXR & 31 & 0 & 32 & 1 & 0 & $64^{\mathrm{b}}$ & $47^{\mathrm{b}}$ \\
\hline \multirow[t]{2}{*}{ B. dichotomus } & \multirow[t]{2}{*}{66} & Control & 1 & 0 & 1 & 0 & 0 & 2 & 2 \\
\hline & & DXR & 23 & 0 & 24.5 & 0 & 0 & $49^{c}$ & $32.5^{\mathrm{c}}$ \\
\hline
\end{tabular}

$\mathrm{C}=$ chromatid break; $\mathrm{IC}=$ isochromatid (chromosomal) break; MA = mean of the total number of metaphases with chromosomal aberrations. *A total of 200 metaphases/species analyzed. **Distinct letters indicate statistical difference by the Tukey test $(\mathrm{P}<0.05)$.

\section{DISCUSSION}

Among the four species tested, M. gouazoubira clearly showed the highest sensitivity to DXR both by frequency and aberration diversity. It could be explained by the hypothesis 
that chromosome fragility may be positively correlated to higher $2 \mathrm{n}$, since $M$. gouazoubira has the highest $2 \mathrm{n}$ of the four species tested: $2 \mathrm{n}=70$. However, this notion was not supported because of the fact that $B$. dichotomus, with $2 \mathrm{n}=66$, showed the lowest sensitivity. Furthermore, there were no statistically significant differences between $M$. americana $(2 \mathrm{n}$ $=52 / 53)$ and $M$. nana $(2 \mathrm{n}=36)$. Another explanation could be a phylogenetic correlation of the genus Mazama; however, this hypothesis is also not viable since there is strong molecular evidence demonstrating that $M$. americana and $M$. nana belong to a different clade and that $M$. gouazoubira is phylogenetically related to B. dichotomus (Gilbert et al., 2006; Duarte et al., 2008). This hypothesis only partially agrees with results seen in M. americana and M. nana, but apparently these results are not sufficiently consistent.

Despite the reasons mentioned above, the hypothesis that chromosome fragility is involved in chromosome evolution in brockets cannot be completely rejected. The information presented in the present study partially agrees with the results from cytogenetic studies (Duarte and Giannoni, 1995; Duarte and Jorge, 1996; Duarte and Merino, 1997; Abril and Duarte, 2008), since higher levels of chromosome aberrations were found in M. gouazoubira, M. americana and M. nana and lower levels in B. dichotomus; however, they failed to explain why the highest levels were seen in M. gouazoubira and not in M. americana and M. nana, two species with higher chromosome evolution rates. These findings may indicate that not all the aberrations expressed in these species are effectively related to chromosome evolution in brockets, and that factors other than phylogeny such as environmental factors may be involved in chromosome fragility.

The tendency toward fragility is one of the theories that explains the existence of karyotypic change in M. americana. Data from different studies suggest that these variants could differentiate species that are geographically isolated, which would result in reproductive isolation. The period to cause this would be inversely proportional to the probability for the occurrence of breaks, inversions, and translocations (Duarte and Jorge, 1996; Duarte and Merino, 1997; Duarte, 1998a). Therefore, the stability of the population depends on chromosomal stability, and when this is deficient, the population could undergo periods of imminent risk of extinction (Duate and Merino, 1997). In the case of M. nana, this event is currently underway due to environmental fragmentation and geographic isolation, which have caused this species to produce large numbers of heterozygotic animals through chromosome rearrangements (Duarte and Merino, 1997). Non-meiotic pairing can cause carriers of rearrangements to be subfertile or even infertile, depending on the number of these rearrangements, which could lead to the extinction of the species (Duarte, 1998b).

Finally, it is necessary to develop further research in order to confirm the exact location of the break points, their molecular composition and their relationship with effective rearrangements documented in these species with high chromosome evolution rates.

\section{ACKNOWLEDGMENTS}

We are grateful to Prof. Dr. Catarina Takahashi of the Faculdade de Medicina de Ribeirão Preto/USP, Brazil, for her assistance and collaboration. We also thank the Brazilian Institute of Forestry Development (IBAMA) for the support given to the Brazilian Cervids Project, to CAPES for the fellowship, and to the Graduate Program in Genetics and Animal Breeding at FCAV/UNESP for the financial support. 


\section{REFERENCES}

Abril VV and Duarte JMB (2008). Chromosome polymorphism in the Brazilian dwarf brocket deer, Mazama nana (Mammalia, Cervidae). Genet. Mol. Biol. 31: 53-57.

Antunes LM and Takahashi CS (1998). Effects of high doses of vitamins C and E against doxorubicin-induced chromosomal damage in Wistar rat bone marrow cells. Mutat. Res. 419: 137-143.

Au WW and Hsu TC (1980). The genotoxic effects of adriamycin in somatic and germinal cells of the mouse. Mutat. Res. 79: 351-361.

Duarte JMB (1998a). Análise Citotaxonômica do Veado Mateiro no Brasil (Mazama americana). In: Análise Citogenética e Taxonômica do Gênero Mazama (Cervidae; Artiodactyla) no Brasil (Duarte JMB). Doctoral thesis em Ciências Biológicas, Instituto de Biociências, Universidade Estadual Paulista, Botucatu.

Duarte JMB (1998b). Análise Citogenética e Taxonômica do Gênero Mazama (Cervidae; Artiodactyla) no Brasil. Doctoral thesis em Ciências Biológicas, Instituto de Biociências, Universidade Estadual Paulista, Botucatu.

Duarte JMB and Giannoni ML (1995). Cytogenetic analysis of the Marsh Deer, Blastocerus dichotomus (Mammalia, Cervidae). Braz. J. Genet. 18: 245-248.

Duarte JMB and Jorge W (1996). Chromosomal polymorphism in several populations of deer (genus Mazama) from Brazil. Arch. Zootec. 45: 281-287.

Duarte JMB and Merino ML (1997). Taxonomia e Evolução. In: Biologia e Conservação de Cervídeos Sul-Americanos: Blastocerus, Ozotoceros e Mazama (Duarte JMB, ed.). Funep, Jaboticabal, 1-21.

Duarte JM, Gonzalez S and Maldonado JE (2008). The surprising evolutionary history of South American deer. Mol. Phylogenet. Evol. 49: 17-22.

Eldridge MD and Johnston PG (1993). Chromosomal rearrangements in rock wallabies, Petrogale (Marsupialia: Macropodidae). VIII. An investigation of the nonrandom nature of karyotypic change. Genome 36: 524-534.

Fontana F and Rubini M (1990). Chromosomal evolution in Cervidae. Biosystems 24: 157-174.

Gilbert C, Ropiquet A and Hassanin A (2006). Mitochondrial and nuclear phylogenies of Cervidae (Mammalia, Ruminantia): Systematics, morphology, and biogeography. Mol. Phylogenet. Evol. 40: 101-117.

Gripenberg U, Huuhtanen S, Wessman M and Nieminen M (1991). A fragile site in the X chromosome of the reindeer (Rangifer tarandus L). Genet. Sel. Evol. 23 (Suppl 1): 135s-139s.

Gülkaç MD, Akpinar G, Ustun H and Ozon KA (2004). Effects of vitamin A on doxorubicin-induced chromosomal aberrations in bone marrow cells of rats. Mutagenesis 19: 231-236.

Miró R, Clemente IC, Fuster C and Egozcue J (1987). Fragile sites, chromosome evolution, and human neoplasia. Hum. Genet. 75: 345-349.

Moorhead PS, Nowell PC, Mellman WJ, Battips DM, et al. (1960). Chromosome preparations of leukocytes cultured from human peripheral blood. Exp. Cell Res. 20: 613-616.

Mudry M, Fundia A, Hick A and Gorostiaga MA (1995). Labilidad cromosómica: una posible explicación en el origen de los reordenamientos cromosómicos en cébidos. Bol. Primatol. Lat. 5: 7-15.

Neitzel H (1987). Chromosome Evolution of Cervidae: Karyotypic and Molecular Aspects. In: Cytogenetics, Basic and Applied Aspects (Obe G and Basler A, eds.). Springer, Verlag, Berlin, 90-112.

Savage JR (1976). Classification and relationships of induced chromosomal structual changes. J. Med. Genet. 13: 103-122.

Vig BK (1971). Chromosome aberrations induced in human leukocytes by the antileukemic antibiotic adriamycin. Cancer Res. 31: 32-37.

Yunis JJ, Soreng AL and Bowe AE (1987). Fragile sites are targets of diverse mutagens and carcinogens. Oncogene 1: 59-69. 